\title{
Tweeting \#humanwaste: A practical theological tracing of \#humanwaste as a trend on Twitter
}

\begin{abstract}
Author:
Jan Albert van den Berg ${ }^{1}$

Affiliation:

${ }^{1}$ Department of Practical

Theology, Faculty of

Theology, University of the

Free State, South Africa

Note:

This article was initially a paper delivered at the Annual conference of the Society for Practical Theology on 23 January 2014 at the University of Pretoria. The article addresses the theme of the conference: Practical theology and human waste in Africa.
\end{abstract}

This article is published in the section Practical Theology of the Society for Practical Theology in South Africa.

Correspondence to:

Jan Albert van den Berg

Email:

vdbergja@ufs.ac.za

Postal address:

PO Box 100985, Brandhof

9324, South Africa

Dates:

Received: 07 Feb. 2014

Accepted: 07 June 2014

Published: 28 Oct. 2014

How to cite this article:

Van den Berg, J.A., 2014

'Tweeting \#humanwaste: A practical theological tracing of \#humanwaste as a trend on Twitter', HTS Teologiese Studies/Theological Studies 70(2), Art. \#2632, 6 pages. http://dx.doi.org/10.4102/ hts.v70i2.2632

\section{Copyright:}

(C) 2014. The Authors. Licensee: AOSIS

OpenJournals. This work is licensed under the

Creative Commons

Attribution License.

\section{Read online:}

Different and divergent facets of human existence are increasingly becoming embodied within a digital domain. The social media platform, Twitter, comprises an important expression of the digital world and social media, but also of popular culture. In a practical theological tracing of the theme of human waste on Twitter, new contents and meaning related to this concept are mapped out in a variety of categories. On the basis of existing and newly developed research methodologies, an exploration is conducted in order to indicate how the digital world can assist in the creation of new empirical realities, hermeneutic outcomes and strategic involvement. In this tracing of human waste as a theme on Twitter, accents of a possible lived spirituality are sounded out and verbalised. It is on the basis of these descriptions that possibilities unfold for new practical theological orientations, both for the present and the future.

\section{Introduction}

In the highly-acclaimed science fiction film, Gravity (2013a), the impact and danger of spacelitter was demonstrated to viewers in a gripping manner by means of 3D-technology. In one scene in the movie, portraying a space-adventure, the brilliant medical engineer on her first shuttle mission, Dr Ryan Stone (Sandra Bullock) says to veteran astronaut Matt Kowalsky (George Clooney): 'Clear skies with a chance of satellite debris' (Gravity 2013b).

This striking film leads the viewer to the important realisation that the problem and impact of human waste ${ }^{1}$ should be understood on multiple levels and within various different contexts. Arising from this important perspective and in conjunction with the theme of the conference ${ }^{2}$, namely human waste, I will explore and discuss the occurrence and meaning of human waste within the space of the social media platform, Twitter, in this contribution. Expression is given to a practical theological reflection which is concrete and contextual: 'This way of thinking is always concrete, local, and contextual, but at the same time reaches beyond local contexts to transdisciplinary concerns' (Müller 2009:205). During this specific research process, a search is conducted within the context of communication technology for associated thematic markers such as, inter alia, the meaning of human waste and the role of popular culture, as embodied on a social media platform such as Twitter. An exploration of and involvement in this reality confirms a relevant and pragmatic practical theological contribution.

The structuring of the presentation is informed by the generally accepted ongoing circular and spiral practical theological movement between practice and theory (Browning 1991:84), and systematised on the basis of descriptive-empirical, normative and pragmatic perspectives. By making use of Osmer's (2008:4) four-question practical theological inquiry ${ }^{3}$ as a grid for mapping this envisaged contribution, my presentation will focus on the following four main aspects:

- Firstly, by asking, 'what is going on?', Twitter will be described as a possible expression of the rise and influence of the new social media phenomenon, creating a so-called third space for reflection 'requiring new logics and evoking unique forms of meaning-making' (Campbell 2013b:4).

- Secondly, the anatomy of human waste in the digital age will be investigated (i.e. 'why is this going on?').

- Thirdly, an exploration of the art of hermeneutics will be conducted in tracing the expressions of human waste as a trend (\#humanwaste) on Twitter (i.e. 'what ought to be going on?').

- Fourthly, the quest for ways in which the tracing of human waste as a trend and the contribution towards possible new and relevant articulations of a pragmatic practical theological involvement will be addressed (i.e. 'how might we respond?').

1.'Rules governing defecation, hygiene and pollution exist in every culture at every period in history' (George 2008:n.p.)

2.Paper delivered at the annual meeting of the Society for Practical Theology in South Africa, held at the University of Pretoria, South Africa (22-24 January 2014). The theme of the conference was 'Practical theology in Africa and human waste'.

3.'What is going on?'; 'Why is this going on?'; 'What ought to be going on?', and 'How might we respond?' 
The addressing of this fourth question will be supported by a seven-step methodology associated with an investigation in transversal rationality, as accommodated within a postfoundational practical theology (Müller 2004:300).

\section{What is going on? Twitter and a digital world}

As background to the interpretation of the reality of a digital world, various scholars (Campbell 2011; Campbell 2013a; Flew 2008; Hassan 2008; Wagner 2012; ${ }^{4}$ point to at least three driving factors currently leading towards further development and demarcation of the digital landscape, namely the:

- continuing development and evolution of the Internet

- connectivity and mobility brought about by the Internet and specific apparatuses such as cellular telephones and tablets

- influence and magnitude of so-called social media.

All three of these factors are addressed in the focus on the use of the social media platform, Twitter.

Twitter, as a well-known social media platform, is indicated as the chosen praxis terrain for the execution of the project. The motivation for this can be found on a variety of levels. Firstly, Twitter is currently one of the most rapidly-growing social media platforms. At the end of April 2014, Twitter had 255 million monthly active users out of a total of a billion registered users with a Twitter account (Smith 2014). With these statistics in mind, Twitter indeed is a good expression of a digital world with the accentuation of aspects such as, inter alia, mobility and fluidity of information. Secondly, by means of its character and dynamics, Twitter offers access to nationally and internationally available empirical data for analysis.

As part of a descriptive-empirical movement of reflection in the present research process, an endeavour is made to describe the dynamics of the involvement with the indicated praxis. Twitter, developed in 2006 (Zappavigna 2012), is generally known as a microblog as it offers the user an opportunity to send a message within the scope of 140 characters (Van Dijk 2011:333; Wagner 2012:120):

These messages, known as 'tweets', can be sent through the Internet, mobile devices such as Internet-enabled phones and iPads, and text messages. But unlike status updates, their strict limit of 140 characters produces at best eloquently terse responses and at worst heavily truncated speech. (Murthy 2013:n.p)

Twitter has been called the 'SMS of the Internet', with the difference that, unlike an ordinary SMS, a Twitter message

\footnotetext{
4.Grieve (2013:115) speculates on the four major features of digital practice in the new future: 'First, the web will be smarter, knowing not just what users say, but what they mean. We will see more semantic content, and the applications that support it ... Second, new media will be mobile and we will see an increase in augmented reality (AR) in which digital media are laid over physical real-world environments .. Third the web will grow more interactive ... Lastly, more and more applications will be outsourced to the cloud, with users accessing information stored on the web remotely from netbooks, tablet computers, smart phones, or other devices ... What combination of these features of new media will win out we cannot tell.'
}

is normally visible to every user of the Twitter platform. The transmission of messages, or 'tweets', is conducted from an individual's Twitter account where the user has the option to create their own profile through the use of a Twitter address or a 'handle' and a biographical description with a photograph and some personal background information (Murthy 2012:1059; Qiu, Lin, Ramsay \& Yang 2012:710). Naturally, all these variable factors provide the constituents for an exceptionally dynamic interaction leading to the following possibility:

Twitter has the potential to increase our awareness of others and to augment our spheres of knowledge, tapping us into a global network of individuals who are passionately giving us instant updates on topics and areas in which they are knowledgeable or participating in real-time. (Murthy 2013:n.p.)

\section{Why is this going on? Thinking before tweeting}

Various authors and researchers have indicated that as citizens of a new digital world, connectedness has become the new passport. In his well-known book, The world is flat: A brief history of the twenty-first century, Friedman (2006:8) writes that the pathways of the world have changed in the wake of, inter alia, the significant developments brought about by various kinds of communication technology, as a result of which more and more people are now able to come into contact with other people across the world. Castells (2006) sums up the situation by referring to:

$[T]$ he new social structure of the Information Age, which I call the network society because it is made up of networks of production, power, and experience, which construct a culture of virtuality in the global flows that transcend time and space. (p. 381)

This passport of connectedness is opening up doorways to new worlds where the connectedness and acceleration of life (Rushkoff 2013:n.p.) is mediated through the transformational mobile device (Sweet 2012:n.p.), a growing and evolutionary Internet availability and the development of associated social media platforms (Campbell 2011:1-18). In their recent study, Aiello et al. (2013) rightly indicated:

As social networking services progressively diffuse in more geographical areas of the world and penetrate increasingly diverse segments of the population, the value of information that is collectively generated on such online platforms increases dramatically. In fact, interactions and communication in social media often reflect real-world events and dynamics as the user base of social networks get wider and more active in producing content about real-world events almost in real-time, social media streams become accurate sensors of real-world events. (p. 1268)

Twitter has been selected as a typical embodiment ${ }^{5}$ of this so-called 'mobinomic world' (Knott-Craig 2012:n.p.) demarcating the formation of a virtual ecosystem of connections across various spheres and layers of life.

5.'With the rising popularity of social networking software, questions continue to emerge regarding new forms of technologically mediated community. Issues being explored include how the blogosphere reshapes our notions of community and how Twitter followers can cultivate a sense of community through creating interlinked Twitter followers can cultivate a sense of
personal networks' (Campbell 2013b:67). 
Accessing the service most likely through wireless Internet mobile devices, Twitter provides a platform for users to make use of this microblogging site 'to present themselves through ongoing "tweets", revealing a self that is both fluid and emergent' (Wagner 2012:120).

\section{What ought to be going on? Practical theological tweeting?}

The interpretation of written texts, as presented in the documents associated with the Christian tradition, as well as of 'the living text of human action' (Brown 2012:112), comprises part of the dynamics of the task of theological hermeneutics (Stiver 2003:178). The interest of practical theology in such practices is confirmed by newer developments that bear the accent of an interest in practically driven events that are contextually and concretely placed within everyday life. In exploring the art of hermeneutics with a view to tracing the expressions of human waste on Twitter, I proceed from the assumption that ' $[t]$ heology is not for Sundays only ... Theology is an everyday affair ... Theology not only articulates beliefs but suggests "designs for living"' (Vanhoozer 2007:7). Underlying this acknowledgement is the conviction that practical theology encapsulates a hermeneutics of the lived religion, in which preference is given to the praxis itself and to the knowledge concerning God that is being developed, found and lived within this praxis (Ganzevoort 2008:11-12).

Underscoring the perception that the culture in which we live is shaping us (Sweet 2012:n.p.) is the belief that the hermeneutics of popular culture ${ }^{6}$ holds the promise of pointing beyond, as Cobb (2005) aptly indicates:

Theology of culture depends upon this kind of trust that our cultural expressions can testify to a reality that transcends them - a reality that is really there, that matters, and in which providence is at work. Theology offers a language to speak about this reality, and can help articulate what is going on in the depths of popular culture ... it is wise to remain open to the more discerning markers of culture. Even of popular culture. (p. 294)

Engaging with popular culture in the expectation that it will reveal 'signals of the transcendent, the presence of grace, rumors of angels' (Vanhoozer 2007:33), I envisage that by means of a hermeneutical practical theology of lived religion, focusing on the praxis of everyday living, tweets regarding human waste can be traced ${ }^{7}$ and described.

Within the practice of the commonplace, which implies actuality and relevance, amongst other aspects, a quest is

6 .... popular culture is therefore the shared environment, practices, and resources of everyday life for ordinary people within a particular society' (Lynch 2005:14).

7.'When I use the word 'tracing', that is, not only because it sounds so well in combination with sacred. It is especially because of the more than adequate meanings it carries. The first is the archaic meaning of traversing or travelling over certain area. The second involves meanings like following or tracking the footprints of someone or something, like when on a hunt. Metaphorically, it can be transposed of someone or something, like when on a hunt. Metaphorically, it can be transposed to studying something in detail, like the history of an idea, the whereabouts of money moving around the world, or one's ancestry. It may also refer to the search for traces, signs, evidence, or remains of something that indicate a certain activity or presence. Tracing then has to do with reconstructing and developing knowledge. The last type of meaning has to do with drawing or sketching. It may be the carefu forming of letters or figures or even certain kinds of decoration, but usually it is a form of copying by hand through a transparent sheet. Here tracing has to do with constructing, modeled after an external reality' (Ganzevoort 2009:5). conducted for the embodiment of a lived religion and the transcription thereof in possible new, normative categories as expressed, inter alia, in a so-called ordinary theology ${ }^{8}$. The development of a postfoundational practical theology, within which an orientation of transversal reality is sustained, comprises a further enlargement of existing hermeneutical orientations, which confirm the importance of empirical descriptions on a multitude of levels. A possible embodiment hereof can be found in a pragmatic theological exploration of the occurrence of the hashtag keyword \#humanwaste (in the title of the article and linking with the theme of the conference) as a theme or trend on Twitter.

\section{How might we respond? Trending and tweeting \#humanwaste}

The hashtag keyword \#humanwaste is an indication of a so-called trend on Twitter. Trending refers to the process of monitoring, detection and extraction in real time of relevant thematically sorted information from the continuous stream of data originating from online sources (Aiello et al. 2013:1268). Although the process of topic detection is a complex process (Aiello et al. 2013:1279), I have made use of the seven-step methodology (Müller 2004:300) associated with an investigation in transversal rationality, as accommodated within a postfoundational practical theology (Müller 2004:300) in the exploration and description of the occurrence of the search phrase, \#humanwaste, on the Twitter platform.

\section{Description of the specific context}

The broader context has already been indicated as the popular and constantly growing social media platform, Twitter, arising from millions of users and thousands of tweets that are sent per minute on a worldwide basis. The focus of the conference, however, falls specifically on 'human waste'. Through the use of the @ and \# symbols, specific search domains on Twitter were explored for this article by making use of the built-in search facility of this particular platform. The @ symbol is used specifically in the search for individuals, as this symbol is used to indicate a so-called personal name or address, generally known as a Twitter handle:

The dialogue between Twitter users occurs through the at-sign (e.g. a user can direct tweets to another user by prefixing a post with an at-sign before the target user's name). (Murthy 2013:n.p.)

By means of the \# symbol, a search is conducted within the flow of tweets selected with a specific focus and thematically grouped under the concerned 'hashtag' ${ }^{\prime}$, in this case \#humanwaste. In this way, the focus falls on a certain thematic selection from a stream of information, with a

8..... ordinary theology in some sense "works" for those who own it. It fits their life experience and gives meaning to, and express the meaning they find within, their own lives. It is highly significant for them because it articulates a faith and a spirituality, and incorporates beliefs and ways of believing, that they find to be salvific - healing, saving, making them whole. Ordinary theology helps people salvific - healing, saving, making them whole.
spiritually and religiously' (Astley 2013:n.p.).

9.'Hashtags are an emergent convention for labelling the topic of a micropost and are a form of metadata incorporated into posts' (Zappavigna 2012:50). 
particular focus on a specific theme. Murthy (2013) therefore indicates:

Any word(s) preceded by a hash sign ' $\#$ ' are used in Twitter to note a subject, event, or association. Hashtags are an integral part of Twitter's ability to link the conversations of strangers together. (n.p.)

\section{Describing and listening to in-context experiences}

After the broad description of the extent and nature of the context - in this case Twitter (http://www.twitter.com) the next important step is to obtain greater clarity by means of empirical research on the nature and contents of tweets that are associated with the theme of 'human waste'. In a preliminary investigation during November 2013, it became clear that @humanwaste and associated Twitter-handles are linked to, inter alia, individuals who choose the concerned name(s) as a Twitter handle, and whose tweets mostly bear themes of a trivial nature ${ }^{10}$ (@humanwaste; http://www. twitter.com). In the search conducted under the hashtag symbol, a stream of tweets with a strong environmental focus are also found, thematically seeking answers for the question as to how the impact and costs of human waste can be positively addressed and counteracted.

\section{Interpretation of experience in collaboration with co-researchers}

Entering the third movement, it is important to first provide some methodological remarks as introduction and to serve as orientation. Not only is the description of the experience important, but the interpretation that the narrator attributes to the experience is also significant. In the third movement of research (Müller 2004:302), the focus thus falls on the meaning or interpretation attributed to the experience by coresearchers. In this regard, Twitter provides an opportunity to work with exceptionally authentic data, as the concerned tweets had not been formulated with the idea that they would be used as research material. Moreover, the different reactions to the initial tweet are also available on Twitter, thus representing an interactive discussion on the theme. There is therefore also the possibility to make use of the interactive character and nature of Twitter, using various actions to engage with characters. Murthy (2013) rightly indicates that:

Anyone can post a tweet directed to @BarackObama or @CharlieSheen, and many do. Additionally, anyone can instantly see a tweet and respond to it. One does not even need to 'know' the other user or have their permission to direct a tweet at them. (n.p.)

\section{Description of the experience of different traditions of interpretations}

Every community displays certain perceptions and behaviours that are shaped by specific traditions and discourses (Müller 2004:302). It is important to identify these perceptions and discourses to develop a greater understanding thereof.
Events and experiences are also interpreted differently by different communities. The goal is an optimal understanding of the different experiences. In the tracing of the meaning of the various tweets, but also of the discussions that arise from the tweets, a new way of approaching practical theological hermeneutics can be established. In this way, the so-called 'theatre of the text' expressing 'the living text of human action' (Brown 2012:112) is given concrete shape within the context of a new practical theological hermeneutics.

\section{Religious reflection and spiritual aspects with the focus on God's presence as experienced in a specific situation}

Regarding the theme of \#humanwaste, George (2008) makes the following remark:

I say that all the world's great faiths instruct their followers how best to manage their excrement, because hygiene is holy. I explain that taking an interest in the culture of sanitation puts them in good company. Mohandas K. Ghandi, though he spent his life trying to rid India of its colonial rulers, nonetheless declared that sanitation was more important than independence. (n.p.)

Taking this observation (with the emphasis on the importance of context) seriously is to acknowledge a practical theology that seeks God's presence in specific experiences, rendering a unique contribution. This is not a forced process, however, but rather an honest endeavour to arrive at an understanding of the co-researcher's religious and spiritual interpretation and experience of God's presence or possibly the lack of such an experience (Müller 2004:302). The researcher's own understanding of God's presence in a given situation renders a valuable contribution to the process of interpretation. In this regard, my own Twitter account (@javdberg) also comprises part of the research and discourse, and I am challenged personally in asking myself how I will respond to the theme of \#humanwaste in my own tweets.

\section{In-depth description of the experiences through interdisciplinary investigation}

In his description of this sixth movement, Müller (2004:303) not only indicates that interdisciplinary discourse comprises an integral part of practical theology, but he also sketches the character of this dialogue: such a discourse may sometimes be difficult and complicated because terms, argumentative strategies, context and the explanation of human behaviour differ from one discipline to the next. Through interdisciplinary discourse, different patterns and actions may, however, be identified within the greater framework leading to a clearer picture, so that greater understanding can be achieved. Interdisciplinary discourse not only includes dialogues between the various theological disciplines, but also dialogues with other scholarly disciplines, traditionally including anthropology, sociology and psychology, amongst others. With regard to the new domain of research, an interdisciplinary discourse with experts from the information technology 
and media studies environment is a prerequisite for further development. However, it remains important to incorporate the different interpretations in a greater overall picture, by means of integration. This greater picture of different interpretations might well be visualised by the creation of a new vocabulary and the articulation of a new language. The creation of a possible new language and meaning is already acknowledged within the media studies field:

New media studies, as much as old media studies, accepts that the communication and representation of human knowledge and experience necessarily involves language and technological systems ... [This] requires us to rethink the intercession of media technologies in human experience. (Dewdney \& Ride 2006:58)

Currently, and in my opinion rightfully so, many classical theological concepts have lost their meaning (Ganzevoort 2013:5-6) within a new digital world described by some as the 'iPod, YouTube and Wii Play' culture (Laytham 2012:1). In search of new and fresh expressions of faith, the possibility exists of articulating a public practical theology, and of providing a space for negotiating new meanings between old and new sources and readers (Ganzevoort 2013:19). Being sensitive towards the process of compiling a future research agenda for practical theology, I would agree that in an evolving digital world, the intersection between new media technologies (e.g. Twitter) and human experience provides a relevant and contextual research domain only accessible through interdisciplinary conversation.

\section{Development of an alternative interpretation}

The ultimate goal of research is not merely to describe and interpret experiences or events, but also to interpret them in such a manner that new meaning will be associated with them. Thus, the focus does not fall on generalisations, but rather on deconstruction and emancipation so that greater possibilities of application will ultimately result. As Müller (2004) indicates:

It rather happens on the basis of a holistic understanding and as a social-constructionist process in which all the co-researchers are invited and engaged in the creation of new meaning. (p. 304)

An endeavour is thus made to obtain a new angle of incidence on the acquired knowledge and understanding by means of the foregoing process and interdisciplinary discourse to arrive at new interpretations and meaning. Such new interpretations and meaning are found and also further developed in tracing \#humanwaste on Twitter. As a practical means of involvement, and arising from the project in the development of alternative meaning ${ }^{11}$, for example, one could consider the possibility of requesting conference delegates to provide comments by means of own tweets with the inclusion of the hashtag keyword \#humanwaste. This could be considered part of the contributions made during a conference such as this one, thereby emphasising that 'social media could be used to manipulate the course of online and offline human dynamics' (Aiello et al. 2013:1268).

11.George (2008:n.p.) is articulating an alternative meaning to the theme of human waste with the following remark: 'How a society disposes of its human excrement is an indication of how it treats its humans too'.

\section{Conclusion}

Ironically, in reading the contents of some of the tweets on Twitter, one may wonder whether those particular tweets have not themselves become part of the problem of \#humanwaste? In fact, the problem of space-litter referred to in the introduction may well comprise a problem of cyberspace. A practical theological research agenda with sensitivity towards the future could thus indeed accord priority to the occurrence, influence and meaning of cyberlitter as a new expression of human waste. Except for charting this new possible and challenging research avenue, the aim of this practical theological contribution was to explore and trace the possible role of a social media platform like Twitter in addressing the theme of \#humanwaste. The engagement with the Twitter-context in this article portrayed a practical theological engagement and strategic involvement with new empirical realities and hermeneutic outcomes.

\section{Acknowledgements Competing interests}

The author declares that he has no financial or personal relationship(s) that may have inappropriately influenced him in writing this article.

\section{References}

Aiello, L.M., Petkos, G., Martin, C., Corney, D., Papadopoulus, S., Skraba et al., 2013, 'Sensing trending topics in Twitter', IEEE Transactions on multimedia 15(6), 1268-1282.http://dx.doi.org/10.1109/TMM.2013.2265080

Astley, J., 2013, 'The analysis, investigation and application of ordinary theology', in J. Astley \& L.J. Francis (eds.), Exploring ordinary theology: Everyday Christian believing and the Church, Ashgate Publishing Company, Surrey. (Kindle edn.).

Brown, S.A, 2012, 'Hermeneutical theory', in B.J. Miller-McLemore (ed.), The Wiley-Blackwell companion to Practical Theology, pp. 112-122, Blackwell Publishing, Oxford.

Browning, D.S., 1991, A fundamental practical theology: Descriptive and strategic proposals, Fortress Press, Minneapolis.

Campbell, H.A., 2011, When religion meets new media, Routledge, London.

Campbell, H.A., 2013a, Digital religion: Understanding religious practice in new media worlds, Routledge, London.

Campbell, H.A., 2013b, 'Community', in H.A. Campbell (ed.), Digital religion: Understanding religious practice in new media worlds, pp. 57-71, Routledge, London.

Castells, M., 2006, End of millennium: The information age, economy, society and culture, 2nd edn., Blackwell Publishing, Oxford.

Cobb, K., 2005, The Blackwell guide to theology and popular culture, Blackwell Publishing, Oxford. http://dx.doi.org/10.1002/9780470774731

Dewdney, A. \& Ride, P., 2006, The new media handbook, Routledge, New York.

Flew, T., 2008, New media: An introduction, 3rd edn., Oxford University Press, Melbourne.

Friedman, T.L., 2006, The world is flat: A brief history of the twenty-first century, Farrar, Strauss and Giroux, New York.

Ganzevoort, R.R., 2008, 'Teaching that matters: A course on trauma and theology', Journal of adult theological education 5(1), 8-19. http://dx.doi.org/10.1558/ jate2008v5i1.8

Ganzevoort, R.R., 2009, Forks in the road when tracing the Sacred: Practical theology as hermeneutics of lived religion, viewed 24 April 2010, from http://www. ruardganzevoort.nl/pdf/2009_Presidential.pdf

Ganzevoort, R.R., 2013, Spelen met heilig vuur: Waarom de theologie haar claim op de waarheid moet opgeven, Uitgeverij Ten Have, Kampen.

George, R., 2008, The big necessity: Adventures in the world of human waste, Portobello, London.

Gravity 2013a, motion picture, viewed 06 December 2013, from http://www.imdb. com/title/tt1454468/

Gravity 2013b, Quotes from Gravity, viewed 10 December 2013, http://www.imdb. com/title/tt1454468/quotes 
Grieve, P.G., 2013, 'Religion', in H.A. Campbell (ed.), Digital religion: Understanding religious practice in new media worlds, pp. 104-118, Routledge, London.

Hassan, R., 2008, The information society: Digital media and society series, Polity Press, Cambridge.

@ humanwaste, viewed 30 November 2013, from https://twitter.com/Humanwaste

\#humanwaste, viewed 30 November 2013, from https://twitter.com/ search?q=\%23humanwaste\&src=typd

Knott-Craig, A., 2012, 'Mobinomics: Mxit and Africa's mobile revolution', Bookstorm Johannesburg. (Kindle edn.)

Laytham, B., 2012, iPod, YouTube, Wii Play: Theological engagements with entertainment, Cascade Books, Oregon.

Lynch, G., 2005, Understanding theology and popular culture, Blackwell Publishing Oxford.

Müller, J.C., 2004, 'HIV/AIDS, narrative practical theology, and postfoundationalism The emergence of a new story', HTS Teologiese Studies/Theological Studies 60(1/2), 293-306. http://dx.doi.org/10.4102/hts.v60i1/2.516

Müller, J.C., 2009, 'Transversal rationality as a practical way of doing interdisciplinary work, with HIV and Aids as a case study', Practical Theology in South Africa 24(2), 199-228.

Murthy, D., 2012, 'Towards a sociological understanding of social media: Theorizing Twitter', Sociology 46(6), 1059-1073. http://dx.doi. org $/ 10.1177 / 0038038511422553$

Murthy, D., 2013, Twitter: Social communication in the Twitter age, Polity Press, Cambridge.

Osmer, R., 2008, Practical theology: An introduction, Wm B. Eerdmans Publishing Co., Grand Rapids.
Qiu, L., Lin, H., Ramsay, J. \& Yang, F., 2012, 'You are what you tweet: Personality expression and perception on Twitter', Journal of Research in Personality 46, 710-718. http://dx.doi.org/10.1016/j.jrp.2012.08.008

Rushkoff, D., 2013, Present shock: When everything happens now, Penguin Group, New York. (Kindle edn.).

Smith, C., 2014, By the number: 116 amazing Twitter statistics, viewed 06 February 2014, from http://expandedramblings.com/index.php/march-2013-by-thenumbers-a-few-amazing-twitter-stats/\#.UvRWOvmSzHO

Stiver, D.R., 2003, 'Theological method', in K.J. Vanhoozer (ed.), The Cambridge companion to postmodern theology, pp. 170-185, Cambridge University Press, Cambridge. http://dx.doi.org/10.1017/CCOL052179062X.010

Sweet, L., 2012, Viral: How social networking is poised to ignite revival, Waterbrook Press, Colorado Springs. (Kindle edn.).

Twitter, 2013, viewed 22 May 2013, from https://twitter.com

Van Dijk, J., 2011, 'Tracing Twitter: The rise of a microblogging platform', International Journal of Media and Cultural Politics 7(3), 333-348. http://dx.doi.org/10.1386/ macp.7.3.333_1

Vanhoozer, K.J., 2007, 'What is everyday theology? How and why Christians should read culture', in K.J. Vanhoozer, C.A. Anderson \& M.J. Sleasman (eds.), Everyday theology: How to read cultural texts and interpret cultural trends, pp. 15-60, Baker Academic, Grand Rapids.

Wagner, R., 2012, Godwired, religion, ritual and virtual reality, Routledge, Hoboken.

World Wide Worx 2013, South African Social Media Landscape 2012, viewed 12 September 2013, from http://www.worldwideworx.com/wp-content/ uploads/2012/10/Exec-Summary-Social-Media-20121.pdf

Zappavigna, M., 2012, Discourse of Twitter and social media, Continuum International Publishing Group, London. 